\title{
The paradox of safety in urban space
}

\author{
Hubert Trammer \\ huberttrammer@wp.pl,h.trammer@pollub.pl \\ Chair of Architecture, Urban Design and Spatial Planning \\ Faculty of Civil Engineering and Architecture, Lublin University of Technology
}

\begin{abstract}
Mutual penetration of pedestrian and vehicle traffic in many cases produces better effects in terms of the quality of staying in the city, and even safety, than their sharp separation. The present article discusses examples of such solutions.
\end{abstract}

Keywords: safety, urban space, pedestrian traffic, vehicle traffic, tram traffic, woonerf, residential zone, pedestrian precinct.

The space of a great many cities worldwide, and not only cities, was transformed in the 20th century - and in many cases still undergoes transformation - in order to introduce a far-reaching segregation in different fields. From the segregation of functions, with separate industrial, service, and residential areas, to segregation of various kinds of traffic, with frequently implemented separation of pedestrian traffic from vehicle traffic by situating them on different levels. Segregation was assumed, and it may intuitively seem, to bring about improved living conditions, including an increase in safety levels. Yet, it often happens otherwise. Mono-functional areas become deserted for many hours each day, while the lack of people deprives them of social control [Gehl 2009, Gehl 2014].

A particularly interesting question is posed by the segregation of traffic. Underpasses and footbridges above the street level theoretically exclude the possibility of collisions between pedestrians and cars. Yet, separation of pedestrian and vehicle traffic on different levels paradoxically, also from the point of view of safety, turns out to be a less fortunate solution than configurations more prone to collisions. In February 2007, a car speeding down Niepodległości Avenue in Warsaw skidded, fell off the road, hit a lamp post and crashed on stairs leading down to a passage under the avenue - an underpass that also offers access to the platform of the Racławicka metro station. On the stairs, the car killed an 81-year-old man [mar 2007]. It was obviously an exceptional situation, which did not bear any general implications concerning the question of safety in underpasses. Yet, it shows that even a complete separation of pedestrian and vehicle traffic by situating them on different levels does not completely exclude the possibility of collision. What is more, this accident can also be viewed not only as a spectacular example of a theoretically impossible situation that indeed happened, but also in a broader context. The crash was caused by the driver's bravado. The layout of Niepodległości Avenue in Warsaw, with sparsely distributed pedestrian crossings, two separate lanes, additionally separated along that section with a fence to prevent pedestrians from crossing the street on the ground, encourages speeding. Speeding cars decrease safety levels on pedestrian crossings in such streets, but in many cases also in the side streets into which cars turn at a greater speed than from streets that slow traffic down. There are known cases of accidents caused by drivers who significantly reduced their speed after exiting a highway, but, momentum-driven, they were still travelling at a much greater speed than they should and if they had not been driving on a highway. Moreover, organisation of traffic based on separating pedestrians from vehicles on different levels does not always mean that they are indeed separated. Instead of crossing the road across different levels, which is arduous and more time-consuming, many pedestrians prefer to stay on the ground level and cross directly, even if it is forbidden. As isolated spaces, footbridges and underpasses are criminogenic in many cases. Criminal acts are facilitated when such passages form long sections without the possibility of changing the route, while remaining at the same time beyond social control, since there are no nearby apartments or services from which they could be observed [Czarnecki, Siemiński 2004]. Underground tram or bus stops and metro stations may also become criminogenic much more often than public spaces located on the ground level. 
Resignation from the segregation of traffic, or its significant limitation, often produces counterintuitive effects. Shared use of a single public space by pedestrians and motor vehicles does not necessarily have to pose threat. For that matter, we may think of the 2007 accident in Warsaw, during which a car landed on stairs leading to an underpass. Even if that accident was evoked to show that underpasses do not guarantee safety, a strong argument against combining pedestrian and vehicle traffic in a single space was delivered by the 2016 terrorist attacks in Nice and Berlin as well as prior and subsequent attacks in the Middle East, in which trucks entered pedestrian zones causing many deaths. Yet, notably, terrorists turned trucks into deadly weapons against pedestrians in zones reserved for exclusive use by the latter, and not shared by pedestrian and vehicle traffic. Let us take a look at examples of spaces for pedestrian traffic and use where contact with vehicle traffic occurs without a clear separation of the two types of traffic. A spectacular example can be found in Leidsestraat (Fig. 1 and 2) in the centre of Amsterdam. The street comprises three sections for pedestrian and tram traffic separated with two bridges over canals carrying additional car and bicycle traffic. Wider than the sections of the street between them, the bridges carry two tram tracks each; two tram stop platforms each, which simultaneously function as pavements; two motor vehicle lanes each, which offer access between the streets on both sides of canals; and two pavements each, located by the bridge railing. The stops situated on the bridges also function as passing loops, since trams operate on a single track in narrow Leidestraat, which limits the space available for them. The track along Leidestraat is used by three tram lines with a two-minute total peak frequency in each direction. In the street, less than ten metres wide, pedestrian traffic co-exists with tram traffic. They are not separated with any physical barriers. The co-existence of tram and pedestrian traffic in a single space can also be observed in many other cities, including those in Poland, such as Chorzów, Gorzów Wielkopolski and Wrocław. The example of Leidestraat in Amsterdam is particularly spectacular given the very limited width of the street, very high pedestrian traffic and two-way high-frequency tram traffic on a track with passing loops, due to which regularity needs to be ensured.

Associated with the Netherlands, the so-called woonerf (English: linving street) is a traffic organisation solution based on the co-existence of pedestrian and vehicle traffic. It gained popularity in Poland owing to the spectacular success of the redevelopment of 6 Sierpnia St. in Łódź (Fig. 3 and 4). Prior to the works, the street was divided into a vehicle lane and narrow pavements, which did not provide an attractive environment for people to stay in. Following a transformation into a woonerf, this fragment of the city began to teem with life. Despite mutual penetration of pedestrian and vehicle traffic, or perhaps because of such a solution, there are no safety issues [Kubecka, Zimny 2016]. As opposed to many living streets (woonerfs), it serves not only local, but also transit, traffic. The Dutch word woonerf means "residential zone". Yet, in Łódź and in other places in Poland, the term is used to refer to strictly public spaces in city centres.
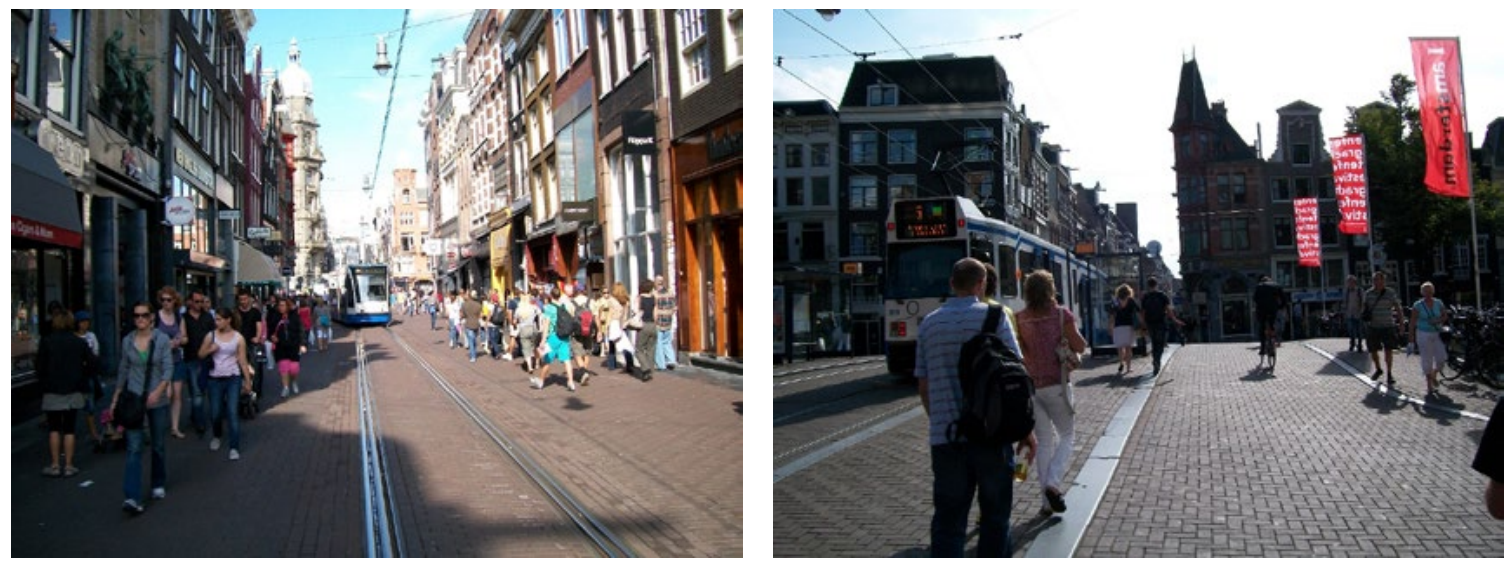

Fig. 1. \& 2. Leidestraat in Amsterdam. Space for pedestrian and tram traffic to co-exist. Top: street between bridges. Bottom: bridge between sections of the street. Source: photo by Hubert Trammer, August 14 ${ }^{\text {th }}, 2009$. 

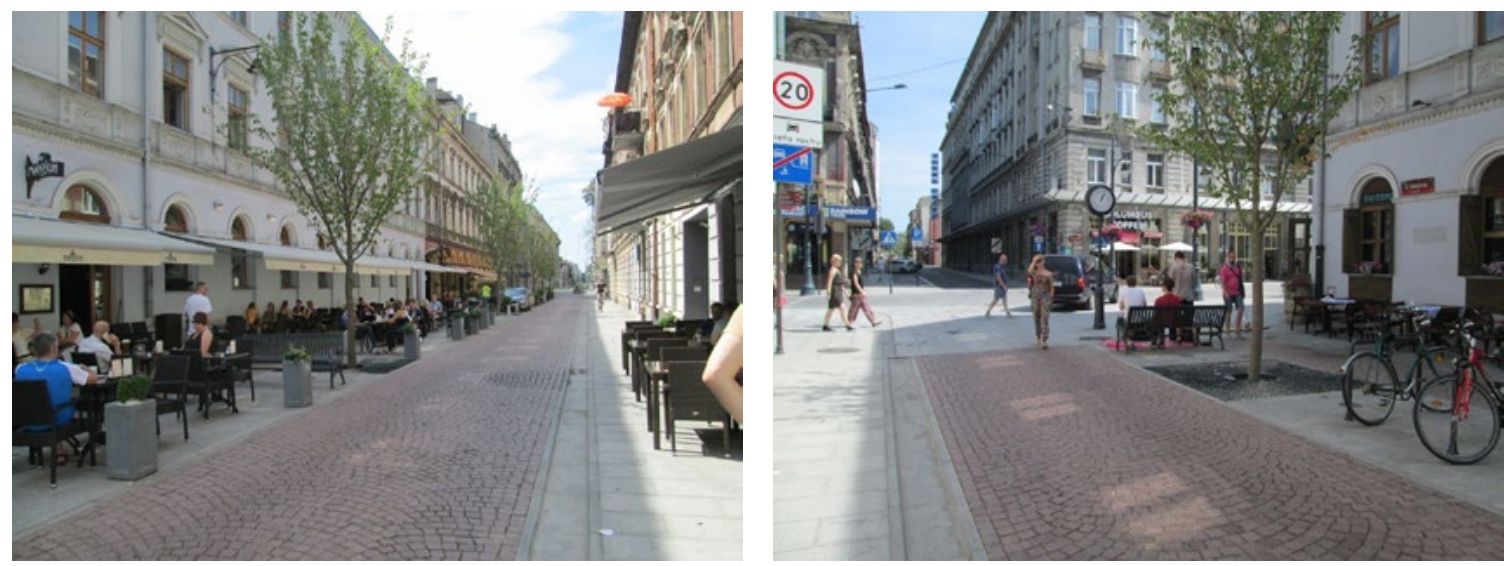

Fig. 3. \& 4. 6 Sierpnia St. in Łódź. Transformation into a woonerf (living street) sparked the popularity of this solution in Poland. Source: photo by Hubert Trammer, August, 10 1014.

As for the relation between pedestrian and other kinds of traffic, what matters is their co-existence in places where their separated routes overlap for the sake of continuity of each of these types of traffic. Different manners of solving such combinations establish different relations between specific kinds of traffic. These are usually places where a vehicle traffic lane can be crossed from one pedestrian pavement to the other. Regarding the most frequent ways to organise traffic in Poland, three most popular types of such places can be distinguished. The first are spaces where a place to cross the street in accordance with general regulations is not indicated in any special way: intersection areas and street sections situated more than 100 metres away from intersections and designated pedestrian crossings; deprived of characteristics that would make no-crossing regulations apply. According to the law, and also in practice, in such spaces vehicle traffic is subordinated to pedestrian traffic. The second type are designated pedestrian crossings without traffic lights. According to regulations, in such instances vehicle traffic is subordinated to pedestrian traffic. Yet, in fact, due to the attitude of many drivers, it is only theoretically so. The volume of pedestrian and vehicle traffic is highly significant in such places. Although an improvement in the drivers' approach can be observed, we are still far behind many countries where pedestrian rights are much more firmly guaranteed by the law. The third type among the most frequently encountered surfaces are designated pedestrian crossings with traffic lights. According to the Polish law, when the light is red for pedestrians, the surface can only be used by vehicles, whereas when pedestrians see the green light, the surface is to be essentially used by them, although vehicle traffic is also allowed in some situations. As for pedestrian crossings at intersections, turning vehicles may cross a pedestrian crossing with a green light, but must yield priority to pedestrians. There is thus a striking inequality between pedestrians and vehicles. The former would enjoy an equal position to cars if they could cross the street on the red light when no vehicles are approaching, or if cars could not cross when pedestrians see the green light.

A solution that is often used in Poland and improves relations between vehicle and pedestrian traffic, reducing discrimination against the latter, consists in elevating pedestrian crossings or even entire intersections. In such cases, a pedestrian crossing or an entire intersection becomes a large speed bump. Thus, pedestrian and car traffic are essentially situated on an equal footing. There is a separate surface that needs to be crossed both between pavements and sections of the street. This surface is situated on the pavement level (Fig. 5 and 6).

In a configuration that subordinates vehicle traffic to pedestrian traffic the continuity of the street is interrupted, whereas the continuity of the pavement or other pedestrian way is not. A common situation in which pedestrians cross the street is replaced with a situation in which cars cross the pavement or a pedestrian way (Fig. 7 and 8). When the pavement is narrow, or the vehicle route is separated with bollards, the situation bears a slight resemblance to an elevated pedestrian crossing. Yet, in some spatial organisation instances, pedestrians may even fail to notice that a vehicle route crosses a pavement or a pedestrian precinct (Fig. 9 and 10). Such a situation occurs for instance in Krupówki pedestrian precinct in Zakopane. It might seem that such a solution is very dangerous and causes many accidents. Yet, it turns out that when entire responsibility for safety is put on drivers and the surface is arranged so that vehicles enter a pedestrian zone, accidents are less likely to happen than when pedestrians need to exercise caution, or even when pedestrians cross the street on the 
green light. There are also examples in which pedestrian precincts are unproblematically crossed by public buses (Fig. 11 and 12).
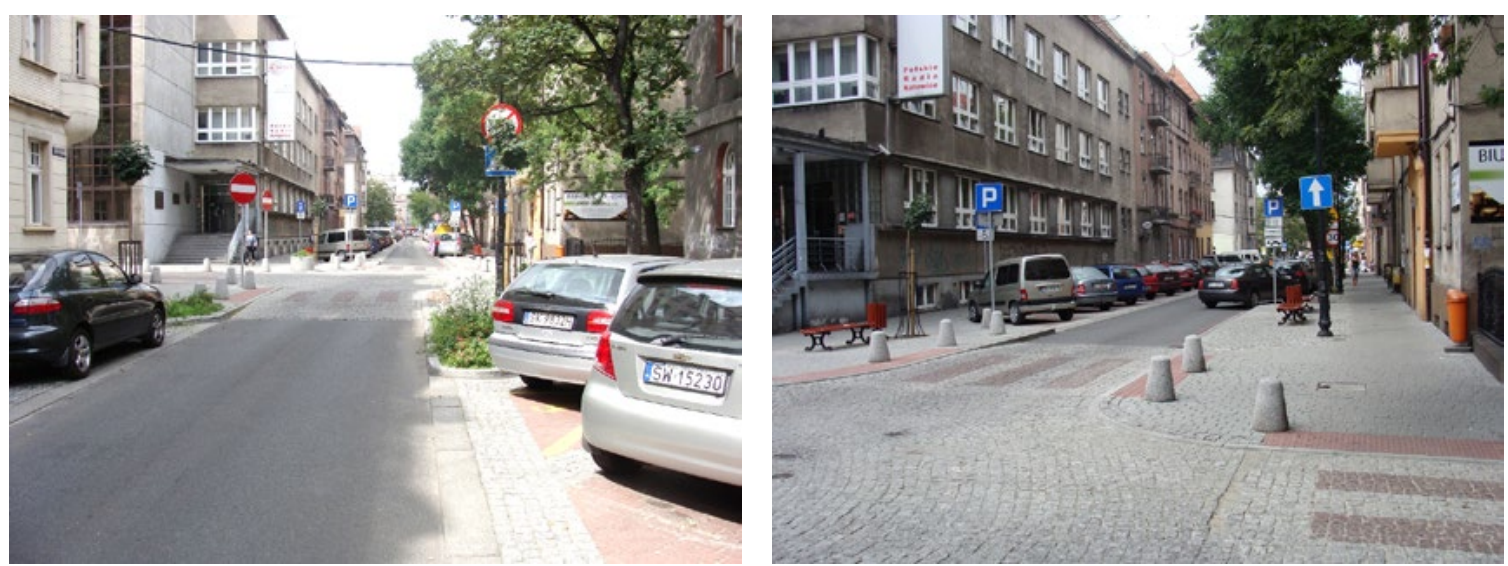

Fig. 5. \& 6. Intersection of Juliusza Ligonia St. and Królowej Jadwigi St. in the centre of Katowice. The surface of the intersection is elevated to the level of the pavement and marked by paving. Source: photo by Hubert Trammer, August 3rd, 2014.
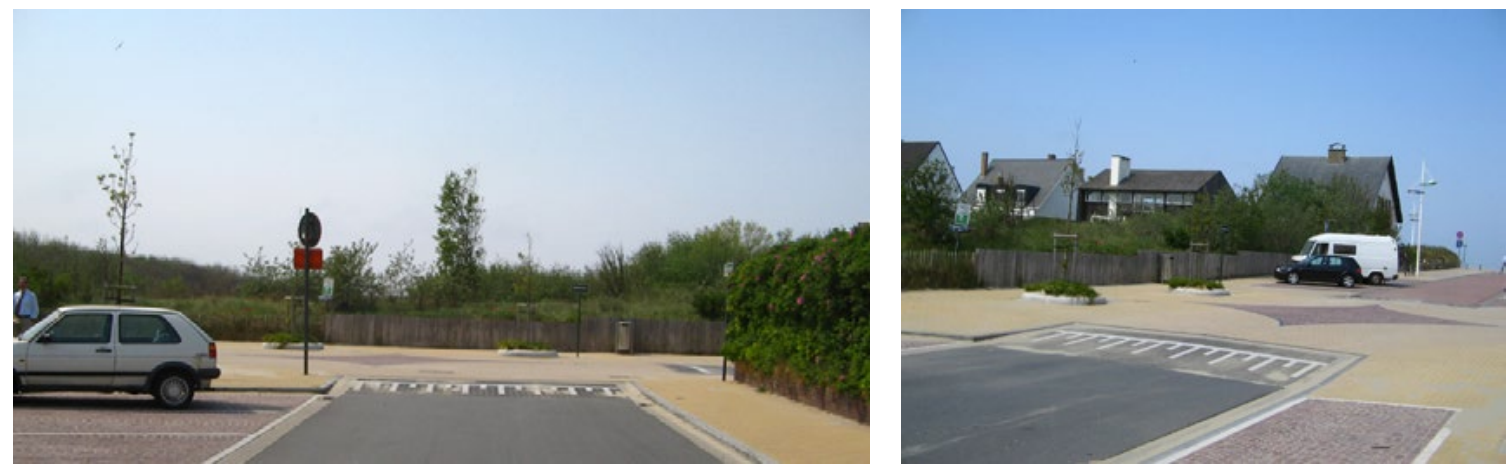

Fig. 7. \& 8. Zeebrugge, Belgium. The surface of the intersection is elevated to the level of the pavements and integrated with their surface. Source: photo by Hubert Trammer, May $4^{\text {th }}, 2007$.
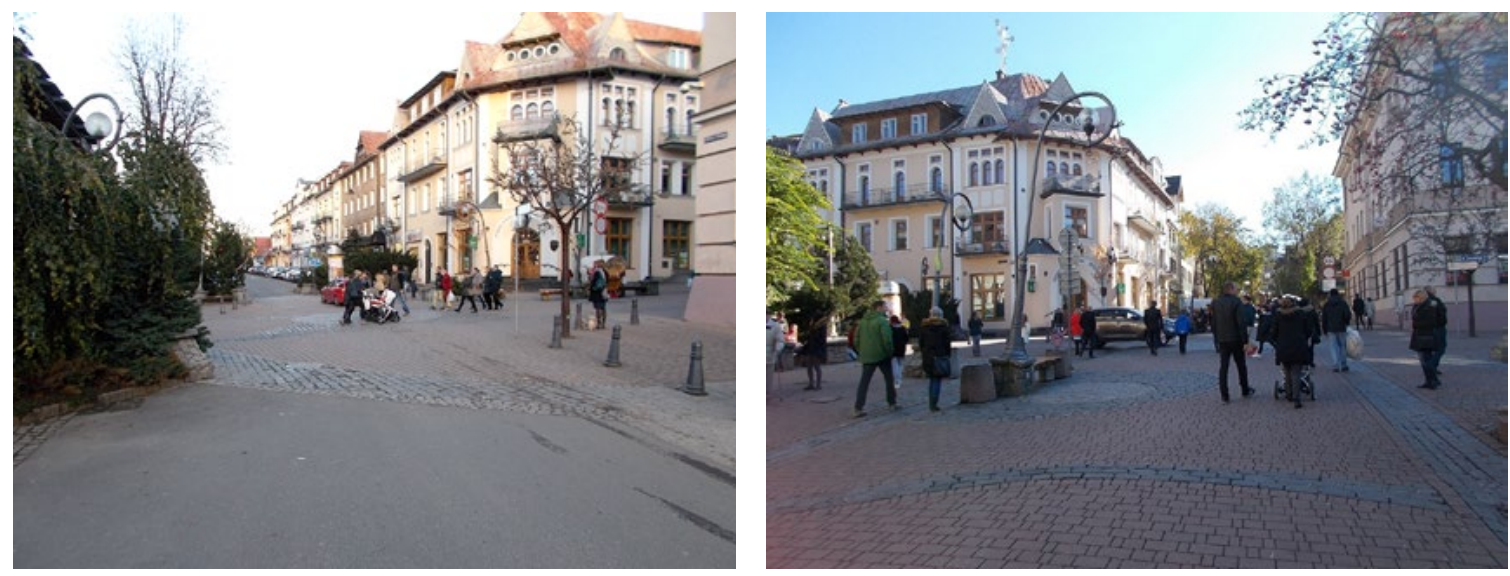

Fig. 9. \& 10. Zakopane town centre. Krupówki promenade breaks the continuity of the perpendicular course of Kościuszki St. and Zaruskiego St. Cars cross the promenade in a place that is not marked in any way. Source: photo by Hubert Trammer, October $23^{\text {rd }}, 2016$. 

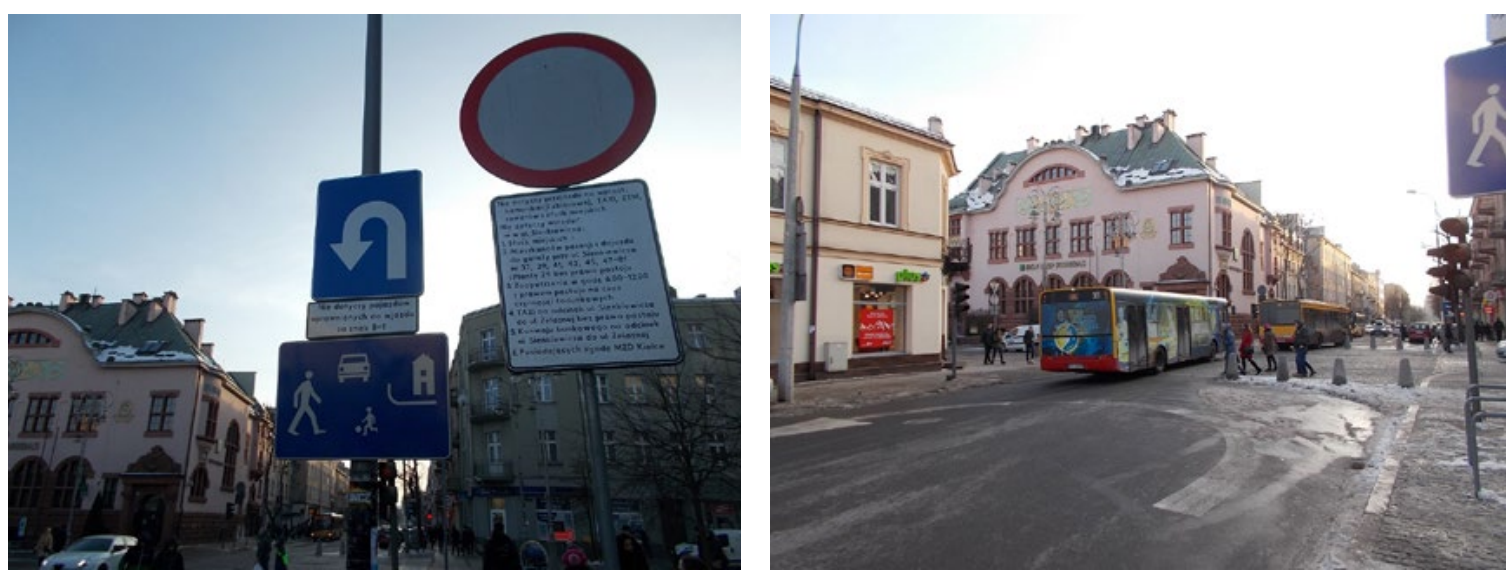

Fig. 11. \& 12. Kielce. Intersection of Sienkiewicza promenade with Paderewskiego St. shaped in a way that privileges pedestrian traffic. Frequently running public buses and other selected types of vehicles can cross the promenade. Source: photo by Hubert Trammer, January $26^{\text {th }}, 2017$.

The presented example of an intersection with a pedestrian precinct - Sienkiewicza St. in Kielce (Fig. 11 and 12) - shows that pedestrian traffic may safely co-exist without separation from very intensive traffic of considerably-sized vehicles. What is more, Paderewskiego St. becomes narrower at the intersection with the precinct, and therefore vehicles need to cross the precinct in alternate traffic, uncontrolled by traffic lights. It might intuitively seem that buses and other authorised vehicles are bound to collide head-on. Yet, the organisation of traffic that compels greater caution in order to prevent accidents between cars increases safety levels. Drivers who need to be careful to avoid collision also pay more attention to pedestrians. Greater caution is also favoured by a change in the road surface.

Various examples discussed above are merely a fraction of countless places where similar solutions function successfully. Yet, the awareness of their good effects is not yet widespread and introduction of such solutions frequently meets with resistance, often also on the part of specialists in road and urban space design. An example here are the woonerfs in Łódź [Kubecka, Zimny 2016]. For this reason, knowledge in this regard should be broadly disseminated.

\section{Bibliography}

[1] Czarnecki, Bartosz, and Waldemar Siemiński. Ksztattowanie bezpiecznej przestrzeni publicznej. Warszawa: Difin, 2004.

[2] Gehl, Jan. Life between Buildings: Using Public Space. Translated by Jo Koch. Washington, Clovelo, London: Island Press, 2011.

[3] Gehl, Jan. Cities for People. Washington, Clovelo, London: Island Press, 2010.

[4] Kubecka, Magdalena, and Bartosz Zimny. "Kierowca syty i pieszy cały." Magazyn Miasta 14 (2016): 133.

[5] mar. "Warszawa: auto potrąciło pasażera... na stacji metra." gazeta.pl 2007 http://wiadomosci.gazeta.pl/wiadomosci/1,114873,3944269.html 